\title{
Ernährung
}

\section{Frühkindliche Darmgesundheit}

\section{Einfluss der Laktose häufig unterschätzt}

Ein gesunder, reifer Darm ist von großer Wichtigkeit für die Gesamtentwicklung des Säuglings. Trägt dieser doch durch Verdauung und Nährstoffaufnahme, Barriere- und Immunfunktion sowie Interaktion mit dem Gehirn maßgeblich zu Gesundheit, Wachstum und Wohlbefinden bei. Bei der Geburt sind die einzelnen Darmabschnitte morphologisch bereits soweit ausgebildet, dass sie ihre Aufgaben erfüllen können. Jedoch ist die volle Funktionsfähigkeit längst nicht erreicht. Säureund Enzymsekretion im Magen-DarmTrakt sowie deren Aktivität reifen in den ersten Monaten nach der Geburt mit dem Alter (autonom) bzw. infolge Anpassung (adaptiv) heran. Diese Reifung ist von der Art und Stärke der auslösenden Faktoren (z. B. Nahrungsexposition) abhängig. Die Rolle der Laktose dabei soll hier näher beleuchtet werden.

\section{Benefits von Laktose in der früh- kindlichen Entwicklung}

Laktose stellt für den Säugling in den ersten Lebensmonaten das wichtigste Nahrungskohlenhydrat dar und kommt natürlicher Weise auch in Muttermilch vor. Im ersten Lebensjahr deckt Laktose etwa die Hälfte (45 \%) des gesamten Energiebedarfs. Des Weiteren hat Milchzucker eine meist unterschätzte Funktion im Knochenstoffwechsel, indem er die Calciumresorption fördert.

„Laktose, die als Disaccharid ins Mikrobiota zu kurzkettigen Säuren, z. B. Buttersäure, verstoffwechselt. Buttersäure dient als Hauptenergielieferant für die Kolonepitehlzellen. Dies stellt den dritten Benefit des Milchzuckers dar", sagt Dozent Dr. Andreas Vécsei, Ambulanz für Gastroenterologie, Hepatologie und Ernährung im St. Anna Kinderspital. Dickdarmlumen gelangt, wird von der
Zeitweise kann es vorkommen, dass der junge Dünndarm mit der bedarfskonformen Laktase-Produktion überfordert ist. In solchen Fällen gelangt vermehrt Laktose ins Colon, was durch gleichzeitig entstehende Gase zu abdominellen Beschwerden führen kann (siehe - Abb. 1).,Klar abzugrenzen ist diese vorübergehende LaktoseMalabsorption von der klassischen primären (genetisch bedingten) Laktose-Intoleranz, die bei kaukasischen Kindern üblicherweise erst im Schulkindalter symptomatisch wird", erläutert Vécsei.

\section{Milch mit Laktase besser als Milch ohne Laktose}

Aufgrund seiner physiologischen Funktionen ist es wichtig, nicht auf Milchzucker im Säuglingsalter zu verzichten. Muttermilch ist der Goldstandard für die Ernährung von Babys. Sie ist besonders leicht verträglich und fördert die Reifung des Darms. Kommen abdominelle Beschwerden beim sensiblen nicht gestillten Säugling häufiger vor, ist fer-

\section{Basiswissen aufgefrischt}

Laktase (B-Galaktosidase) spaltet den Großteil des Milchzuckers in der Dünndarmschleimhaut in Glukose und Galaktose. Diese enzymatische Aktivität erreicht im oberen Jejunum ihr Maximum und ist im lleum kaum mehr nachweisbar. Die Laktaseaktivität bei Neugeborenen wächst mit steigendem Milchzuckerangebot (= adaptive Laktasebildung).

mentierte Formula mit aktiver Laktase ein interessantes Konzept, um die physiologische Laktoseverdauung zu unterstützen. Die aktuelle Datenlage liefert laut Vécsei allerdings keinen Beweis der Wirksamkeit von laktosefreien oder -reduzierten Kuhmilchfomulanahrungen bei Säuglingskoliken.

Pädiatrie \& Pädologie 2015 · 50:281 DOI 10.1007/s00608-015-0325-9

Online publiziert: 10. November 2015

C) Springer-Verlag Wien 2015

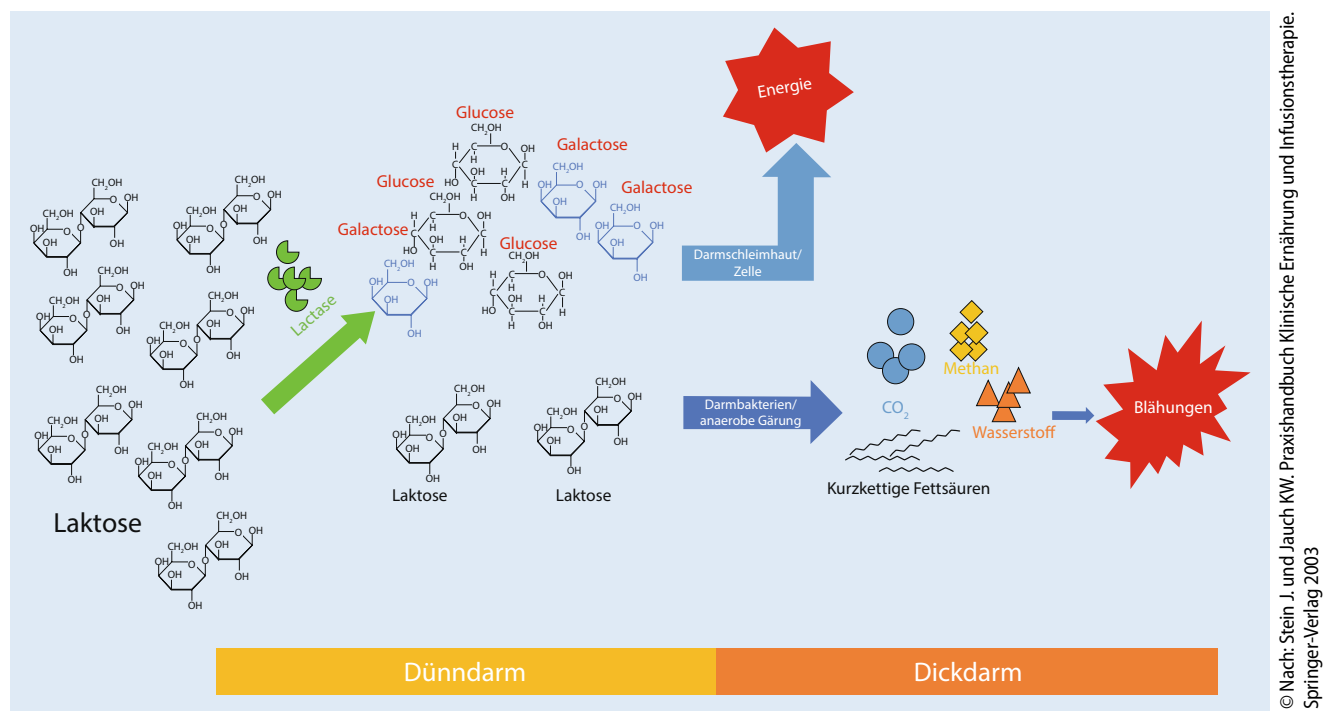

Abb. 1 \ Vereinfachte Darstellung des Laktose-Stoffwechsels 